\title{
Properties, production, and applications of camelid single-domain antibody fragments
}

\author{
M. M. Harmsen • H. J. De Haard
}

Received: 13 June 2007 /Revised: 25 July 2007 / Accepted: 30 July 2007 / Published online: 18 August 2007

(C) Springer-Verlag 2007

\begin{abstract}
Camelids produce functional antibodies devoid of light chains of which the single N-terminal domain is fully capable of antigen binding. These single-domain antibody fragments (VHHs or Nanobodies ${ }^{\circledR}$ ) have several advantages for biotechnological applications. They are well expressed in microorganisms and have a high stability and solubility. Furthermore, they are well suited for construction of larger molecules and selection systems such as phage, yeast, or ribosome display. This minireview offers an overview of (1) their properties as compared to conventional antibodies, (2) their production in microorganisms, with a focus on yeasts, and (3) their therapeutic applications.
\end{abstract}

Keywords Single-domain - Microbial production · Yeast . Glycosylation

\section{Introduction}

The field of recombinant antibody technology has rapidly progressed during the last two decades, mainly because of the interest in their human therapeutic use. The ability to select specific human antibodies by display technologies

\footnotetext{
M. M. Harmsen ( $\square)$

Institute for Animal Science and Health (ID-Lelystad) of

Wageningen University and Research Centre,

Edelhertweg 15,

8219 PH Lelystad, The Netherlands

e-mail: michiel.harmsen@wur.nl

H. J. De Haard

Ablynx N.V.,

Technologiepark 4,

9052 Zwijnaarde, Belgium
}

and to improve their affinity, stability, and expression level by molecular evolution has further boosted the field. Whole antibodies are complex molecules that consist of heavy and light chains (Fig. 1a). They contain an N-linked oligosaccharide attached to the second heavy-chain constant domain $(\mathrm{CH} 2)$ that is essential for antibody effector functions such as antibody-dependent cellular cytotoxicity (ADCC), complement-dependent cytolysis (CDC), and for retaining a long serum half-life.

Although isolated antibody heavy (Utsumi and Karush 1964) and light chains (Yoo et al. 1967) can retain antigenbinding specificity, their affinity and solubility is often reduced (Ward et al. 1989). However, the paired N-terminal variable domains of heavy $(\mathrm{VH})$ and light $(\mathrm{VL})$ chains are sufficient for antigen binding (Sundberg and Mariuzza 2002). Such antibody fragments can be produced as monovalent antibody fragment $(\mathrm{Fab})$ or as single-chain $\mathrm{Fv}$ $(\mathrm{scFv})$ where the $\mathrm{VH}$ and $\mathrm{VL}$ domains are joined by a polypeptide linker (Fig. 1a). Their production in microbial cells is often cumbersome, especially when producing multivalent formats, because of the requirement for domain association.

The discovery that camelids (bactrian camels, dromedaries, and llamas) produce functional antibodies devoid of light chains (Hamers-Casterman et al. 1993) formed a further breakthrough because their single N-terminal domain (VHH, also referred to as Nanobody ${ }^{\circledR}$ ) binds antigen without requiring domain pairing. These heavy-chain antibodies also lack the $\mathrm{CH} 1$ domain, which in a conventional antibody associates with the light chain and to a lesser degree interacts with the $\mathrm{VH}$ domain (Fig. 1b). Although single-domain antibodies later were also identified in particular cartilaginous fish (Greenberg et al. 1995), most research on the biotechnological application of singledomain antibodies was done using camelids because of 
Fig. 1 Schematic diagram of conventional (a) and heavychain (b) antibodies and fragments thereof. Variable domains derived from the antibody heavy $(V H)$ and light $(V L)$ chains are shaded dark gray and light gray, respectively, whereas constant domains $(\mathrm{CH}$ and $\mathrm{CL})$ are not shaded. Note the absence of the light chain and $\mathrm{CH} 1$ domain in heavy-chain antibodies. Antibody domains that pair by noncovalent interactions are indicated by overlaying them. The B-subunits of naturally pentamerizing toxins that are used to generate pentabodies are indicated as hatched spheres

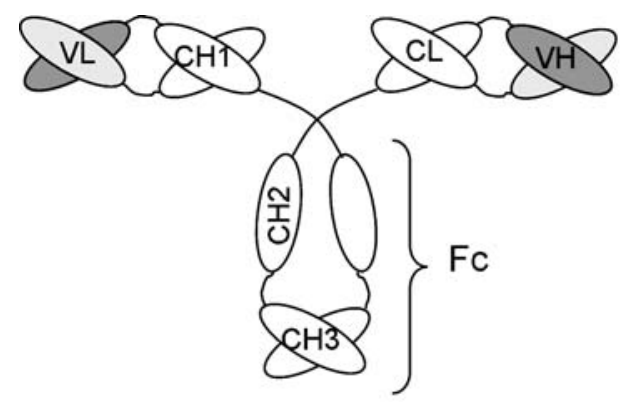

a

Conventional IgG

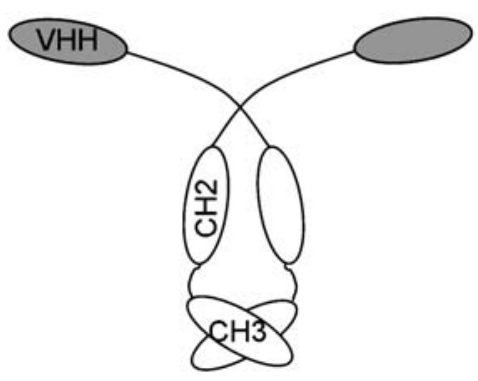

VHH
VHH $\left(\right.$ Nanobody $\left.{ }^{\circledR}\right)$

b

Heavy-chain IgG
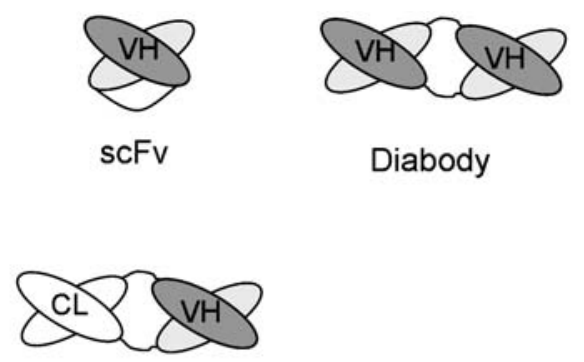

$\mathrm{Fab}$ their ease of handling, including immunization. Methods to isolate antigen-specific VHHs from immune (ArbabiGhahroudi et al. 1997; Van der Linden et al. 2000a), nonimmune (Tanha et al. 2002; Yau et al. 2003; Verheesen et al. 2006), or semisynthetic (Goldman et al. 2006) libraries using phage, yeast, or ribosome display are now well established. For further reading on these topics, we refer to recently published reviews (Muyldermans 2001; Dufner et al. 2006).

\section{Properties}

Sequence analysis (Hamers-Casterman et al. 1993; Muyldermans et al. 1994; Vu et al. 1997; Harmsen et al. 2000) and elucidation of the crystal structure (Desmyter et al. 1996, 2001; Spinelli et al. 1996) has revealed several structural features of VHH domains. Similar to conventional VH domains, VHHs contain four framework regions (FRs) that form the core structure of the immunoglobulin domain and three complementarity-determining regions (CDRs) that are involved in antigen binding. This contrasts with shark single-domain antibodies that have a vestigial CDR2 that does not contribute to antigen binding (Streltsov et al. 2004). As compared to human VH domains, the VHH FRs show a high sequence homology of more than $80 \%$, and their 3D structures can be superimposed (Muyldermans et al. 2001; Holliger and Hudson 2005).
The most characteristic feature of VHHs is the presence of amino acid substitutions at four FR2 positions (positions 37, 44, 45, and 47; Kabat numbering) that are conserved in conventional $\mathrm{VH}$ domains and that are involved in forming the hydrophobic interface with VL domains. Occasionally, antigen-binding single-domain antibody fragments that lack these characteristic FR2 substitutions are isolated from camelids. These fall into two groups. The low-affinity binders isolated from a nonimmune library originated from conventional antibodies, presumably because of the polymerase chain reaction crossover cloning artifact, as they were linked to the $\mathrm{CH} 1$ domain (Tanha et al. 2002). We refer to these as VHH-like conventional VHs. However, such single-domain antibody fragments with conventionallike FR2 sequences that bind antigen with high affinity are isolated from immune libraries with the high efficiency of about 10\% (Conrath et al. 2001a; Saerens et al. 2004; Harmsen et al. 2005a, 2007), which equals their presence in unselected libraries (Harmsen et al. 2000). This is not expected when such clones originate from a cloning artifact. Unlike the clones isolated by Tanha et al. (2002), these clones often contain a hydrophilic residue (mostly arginine) at position 103. This substitution is probably important for their single-domain nature (Desmyter et al. 2001) because conventional antibodies contain a highly conserved hydrophobic residue (tryptophan) at this position that contacts VL. This suggests that these represent functional $\mathrm{VHH}$ domains derived from recombination of 
conventional VH gene segments with heavy-chain constant gene segments during $\mathrm{B}$ cell maturation. This was confirmed by the absence of the $\mathrm{CH} 1$ domain when such $\mathrm{VHH}$ domains were reisolated from the original immune repertoire using a CDR3-specific primer (De Haard, unpublished observation). Therefore, we refer to these as conventionallike VHH domains. Although the increased hydrophilicity of VHHs predominantly relies on the aforementioned changes in the former VL interface, some amino acids at positions that form a slightly hydrophobic patch on conventional VH domains that contacts $\mathrm{CH} 1$ (Lesk and Chothia 1988) are also changed into hydrophilic residues in VHHs (Muyldermans et al. 1994; Harmsen et al. 2000).

Furthermore, the CDRs of VHHs contain some characteristic features. Firstly, the N-terminal part of CDR1 is more variable (Vu et al. 1997; Harmsen et al. 2000; Nguyen et al. 2000). Secondly, many dromedary VHHs have an extended CDR3 that is often stabilized by an additional disulfide bond with a cysteine in CDR1 or FR2 (Muyldermans et al. 1994) resulting in the folding of the CDR3 loop across the former VL interface (Desmyter et al. 1996). A particular subfamily of llama VHHs (VHH3) also contains an extended CDR3 that is stabilized by an additional disulfide bond with a cysteine at position 50 in FR2. However, VHHs of this subfamily are rarely isolated, and most llama VHHs have CDR3 loops similar in length to those found in human VHs.

VHHs have many advantages for biotechnological applications, which are summarized in Table 1. An important advantage is their high microbial production level (see next section).

Several advantages result from their single domain nature. Thus, VHH libraries generated from immunized camelids retain full functional diversity. This contrasts with the diminished diversity of conventional antibody libraries because of reshuffling of $\mathrm{VL}$ and $\mathrm{VH}$ domains during library construction. As a result, high-affinity antigenbinding VHHs can be isolated by directly screening a limited number of clones from immune libraries without prior selection using display technologies (Frenken et al.
2000; Harmsen et al. 2005b). Furthermore, the singledomain nature facilitates subsequent molecular manipulation. For example, for many applications, it is advantageous to engineer monovalent antibody fragments into multivalent formats to increase functional affinity (termed avidity) or to produce bispecific antibody fragments that can simultaneously bind to different antigens. Such molecules (diabodies, Fig. 1a) can be produced using conventional recombinant antibodies using linkers between the $\mathrm{VH}$ and VL domains of a specific length, although this often results in aggregation and reduced affinity because of mispairing of VH and VL domains (Glockshuber et al. 1990; Whitlow et al. 1993). VHHs are more suitable for production of such formats because they allow more flexible linker design, which is important for simultaneous binding of multivalent antigens, without the problems posed by domain mispairing. Thus, several functional trivalent-bispecific VHHs have been successfully produced (Coppieters et al. 2006; Roovers et al. 2007).

The use of mixtures of a limited number of monoclonal antibodies (oligoclonal antibodies) is advantageous over single monoclonal antibodies for particular applications, such as toxin neutralization (Nowakowski et al. 2002). Because of regulatory requirements, such oligoclonals are preferentially produced from single cells. Again, VHHs are predicted to be more suitable for single-cell production of oligoclonals because of the absence of domain mispairing, although this is yet to be demonstrated experimentally.

Contrary to conventional antibodies, VHHs have been shown to remain functional at $90^{\circ} \mathrm{C}$ (Van der Linden et al. 1999) or after incubation at high temperatures (Van der Linden et al. 1999; Perez et al. 2001). This high apparent stability is mainly attributed to their efficient refolding after chemical or thermal denaturation and to a lesser extent because of an increased resistance against denaturation (Perez et al. 2001; Dumoulin et al. 2002; Ewert et al. 2002). The increased apparent stability is probably due to an increased hydrophilicity of the former VL interface region because a "camelized" human VH fragment that contains

Table 1 Advantages of camelid single-domain antibody fragments as compared to conventional antibody fragments

\begin{tabular}{ll}
\hline Advantage & Molecular basis \\
\hline Facile genetic manipulation & Single-domain nature \\
Increased functional size of immune libraries & No decrease in library size because of reshuffling of VL and VH domains \\
Facile production of multivalent formats & More flexible linker design and no mispairing of VL and VH domains \\
Facile production of oligoclonal preparations from single cells & No mispairing of VL and VH domains \\
High physicochemical stability & Efficient refolding due to increased hydrophilicity and single-domain nature \\
High solubility & Increased hydrophilicity \\
Recognition of hidden antigenic sites & Small size and extended flexible CDR3 \\
Rapid tissue penetration, fast clearance & Small size \\
Well expressed & Efficient folding due to increased hydrophilicity and single-domain nature
\end{tabular}

See text for references 
several of the hallmark hydrophilic amino acid residues of VHHs was more stable than the original VH fragment (Davies and Riechmann 1995, 1996), whereas "decamelization" of a $\mathrm{VHH}$ to mimic a $\mathrm{VH}$ domain reduces its thermodynamic stability (Conrath et al. 2005). In addition to these specific mutations, the packing of extended CDR3 loops against this former VL interface contributes to domain stability (Bond et al. 2003). Furthermore, refolding of VHHs only requires domain refolding, whereas conventional antibodies also require association of $\mathrm{VH}$ and $\mathrm{VL}$ domains.

VHHs can also recognize antigenic sites that are normally not recognized by conventional antibodies such as enzyme active sites (Lauwereys et al. 1998; De Genst et al. 2006) and conserved cryptic epitopes (Stijlemans et al. 2004). This facilitates their use as enzyme inhibitors or in diagnosis of trypanosome infections. The ability to recognize these recessed antigenic sites has been attributed to their smaller size and the ability of the extended CDR3 loop to penetrate into such sites (Desmyter et al. 1996; De Genst et al. 2006). It is interesting to note that this structurefunction relation is also observed in a rare example of a broadly reactive human $\mathrm{mAb}$ that recognizes the recessed and conserved CD4-binding cavity of human immunodeficiency virus type 1 gp120 by virtue of an extended CDR3 (Zwick et al. 2003). With respect to antigen binding, the single-domain nature could be a disadvantage for binding to small antigens such as haptens and peptides because these normally bind in a groove or cavity at the VH-VL interface (Sundberg and Mariuzza 2002). Indeed, llamas immunized with clenbuterol developed conventional but not heavychain antibodies against this hapten (Lange et al. 2001). However, hapten- and peptide-binding VHHs have been successfully isolated using strong selection systems (Spinelli et al. 2000; Yau et al. 2003; Alvarez-Rueda et al. 2007; Harmsen et al. 2007). The affinities of VHHs are generally comparable to those of conventional antibody fragments (Muyldermans et al. 2001). Occasionally, VHHs with affinity constants $\left(K_{\mathrm{D}}\right)$ as low as $100 \mathrm{pM}$ are isolated (Saerens et al. 2004; De Genst et al. 2006; Harmsen et al. 2006), which equals the affinity ceiling proposed for natural antibodies (Sundberg and Mariuzza 2002).

Because of their small size of about $15 \mathrm{kDa}$, VHHs rapidly pass the renal filter, which has a cutoff of about $60 \mathrm{kDa}$, resulting in their rapid blood clearance. In addition, the small size results in a fast tissue penetration. This is advantageous for targeting of VHHs coupled to toxic substances to tumors (Cortez-Retamozo et al. 2004), in vivo diagnosis using imaging, and treatment of snake bites (Harrison et al. 2006). However, for other therapeutic applications, such as treatment of infectious or inflammatory diseases, the short serum half-life of about $2 \mathrm{~h}$ (Cortez-Retamozo et al. 2002; Harmsen et al. 2005a) is a disadvantage.

\section{Production in microorganisms}

Although a fully active nonglycosylated IgG was recently produced at high level in Escherichia coli, most functional complete antibodies can only be efficiently produced using mammalian cells, especially when their appropriate glycosylation is required for therapeutic applications. However, antibody fragments that lack the $\mathrm{Fc}$ with its N-linked oligosaccharide are preferably produced in microbial systems (Arbabi-Ghahroudi et al. 2005). These have a shorter development time from gene to product and require simple well-established fermentation conditions that can be performed on large-scale resulting in costs of goods that can be as low as $\$ 1$ per gram heterologous protein (Estell 2006). Most large-scale microbial production systems are based on $E$. coli, yeasts, or filamentous fungi. Production in $E$. coli can be done by secretion into the oxidizing periplasmic space or expression in the reducing cytosol. The latter requires the often cumbersome refolding of antibody fragments (Arbabi-Ghahroudi et al. 2005). Using eukaryotic microbial hosts, antibody fragments are generally produced by targeting to the secretory pathway. This enables efficient disulfide bond formation, addition of $\mathrm{N}$ linked oligosaccharide, and secretion of soluble, correctly folded product to the culture medium.

VHHs have often been produced in E. coli (ArbabiGhahroudi et al. 1997; Rahbarizadeh et al. 2005). There is only one example of VHH production in filamentous fungi, which resulted in limited proteolytic degradation of the secreted product (Joosten et al. 2005) because of the high levels of proteases secreted by filamentous fungi (Gerngross 2004). VHHs have also often been produced in the yeast Saccharomyces cerevisiae (Frenken et al. 2000; Thomassen et al. 2002; Van der Vaart 2002). VHH production by the favored yeast expression host Pichia pastoris was only recently described (Rahbarizadeh et al. 2006). Occasionally, yeast-produced VHHs are N-glycosylated (Frenken et al. 2000; Harmsen et al. 2005a). This can affect antigen binding (Van der Vaart et al. 2006). Furthermore, it could complicate their therapeutic use because the addition of yeast-specific high-mannose oligosaccharides results in a high immunogenicity and decreased serum half-life because of binding to specific mannose receptors on cells of the reticulo-endothelial system (Sethuraman and Stadheim 2006).

Although VHHs are generally well produced in microorganisms, the production level of different clones can vary by a factor of 100 (Frenken et al. 2000; Harmsen et al. 2005b; Van de Laar et al. 2007). Several VHH sequence patterns can be associated with their production level. First, the presence of a potential $\mathrm{N}$-linked glycosylation site often increases production levels in yeast (Sagt et al. 2000). Second, in our experience (Harmsen, unpublished observations), conventional-like VHHs are generally produced at 
reduced levels in yeast. This contrasts with the reported efficient production in E. coli of VHH-like VHs (Tanha et al. 2002) but is consistent with the increased production level of "camelized" conventional VH domains in E. coli (Davies and Riechmann 1995). Third, the presence of unpaired C-terminal cysteines reduces expression levels (Simmons et al. 2006). Fourth, replacement of hydrophobic residues of conventional $\mathrm{VH}$ domains normally interacting with $\mathrm{CH} 1$ increased $\mathrm{scF} v$ production in $E$. coli (Nieba et al. 1997), suggesting that the hydrophilic mutations that naturally occur at these positions in VHHs also contributes to their high expression level. However, there are many examples of VHHs that differ by only a few amino acids and are produced at highly variable levels where the exact amino acid change responsible for the difference in production level is difficult to predict (Frenken et al. 2000; Harmsen et al. 2005b). Furthermore, without such knowledge, VHH production can be improved by random molecular evolution using deoxyribonucleic acid shuffling (Van der Linden et al. 2000b), as has often been done for conventional antibody fragments (Dufner et al. 2006). The high refolding capability of VHHs, which is a consequence of their sequence, has also been correlated with a high production level in E. coli (Jespers et al. 2004; Olichon et al. 2007).

In addition to the nature of the $\mathrm{VHH}$, host factors affecting VHH production have been identified. In baker's yeast, the specific VHH production rate is correlated with growth rate (Thomassen et al. 2005) and can be up to fivefold increased by growing on ethanol as the carbon source (Van de Laar et al. 2007). Supplementation of the medium with sorbitol, casamino acids, or ethylenediamine tetraacetic acid improves VHH production by P. pastoris (Rahbarizadeh et al. 2006).

In addition to monovalent VHHs, several expression formats for the production of VHH multimers have been described (Fig. 1b). These include genetic fusions of two (Conrath et al. 2001b; Harmsen et al. 2005a) or three VHHs (Coppieters et al. 2006; Roovers et al. 2007) that either recognize different antigens or the same repeating antigen to increase functional affinity. Although such VHH fusions are less efficiently produced than their monovalent versions, their production level exceeds that of their conventional-antibody-based fusion counterparts without aggregation or low solubility. However, antigen binding by the C-terminal VHH in such fusions can be compromised (Conrath et al. 2001b) presumably because of steric hindrance by the N-terminal VHH. The avidity of VHHs has also been strongly increased using genetic fusions to the B-subunits of an E. coli toxin that selfassembles into a homopentamer (Zhang et al. 2004), resulting in pentameric recombinant antibodies ("pentabodies," Fig. 1b).
VHHs on their own cannot recruit effector functions such as ADCC and CDC. This limits their therapeutic application. Although such effector functions can be indirectly recruited using bispecific (conventional) antibody fragments binding to host immunoglobulin (Holliger et al. 1997), it may be more efficient to recruit these functions by fusing VHHs to host Fc domains. Production of such functional antibodies requires the correct glycosylation of the $\mathrm{CH} 2$ domain, which until recently could only be accomplished using higher eukaryotic cells (Nguyen et al. 2003) but not by microbial production. However, this may now be feasible using $P$. pastoris strains with an engineered glycosylation machinery that are able to produce proteins with a specific human glycoform (Hamilton et al. 2006). Furthermore, transgenic mice containing hybrid llama/ human antibody loci that contain llama $\mathrm{V}$ regions and human $\mathrm{D}, \mathrm{J}$, and $\mathrm{C}$ regions have recently been used to generate human heavy-chain antibodies in mice (Janssens et al. 2006).

\section{Therapeutic applications}

Although VHHs are highly suited for applications that require a high stability, such as use in shampoo for the prevention of dandruff (Dolk et al. 2005), as capturing reagents in immunoaffinity purification (Verheesen et al. 2003), or use in biosensors (Pleschberger et al. 2004), we would like to focus on their therapeutic applications, which are more challenging. Several VHHs are now being studied for use in various disease areas, including oncology (Revets et al. 2005) and in infectious, inflammatory, and neurodegenerative diseases (Table 2).

VHHs are especially suited for oral immunotherapy because of their resistance against extremes of $\mathrm{pH}$ and the capacity to bind to the target at high concentrations of chaotropic agents (Dumoulin et al. 2002, 2003). Administration to piglets of a VHH that effectively prevents intestinal attachment of $E$. coli bacteria that cause diarrhea resulted in poor in vivo protection (Harmsen et al. 2005b) because of degradation by gastrointestinal proteases (Harmsen et al. 2006). However, by selection for proteolytic stability, a VHH could be isolated from the original library that was not degraded in vivo (Harmsen et al. 2006). VHHs that successfully prevented diarrhea caused by rotavirus in a mouse model were similarly selected for resistance against the acidic environment of the stomach (Van der Vaart et al. 2006). Alternatively, VHH proteolysis can be prevented by local VHH production using natural gut commensal bacteria. Thus, diarrhea could also be prevented by lactobacilli that produce rotavirus-neutralizing VHHs fused to a cell surface anchor (Pant et al. 2006). Treatment of caries, caused by Streptococcus mutans, with VHHs conferred only limited 
Table 2 Examples of therapeutic applications of camelid VHHs

\begin{tabular}{|c|c|c|c|c|c|}
\hline Disease & Pathogen & Target antigen & $\begin{array}{l}\text { VHH valency for } \\
\text { disease target }\end{array}$ & Additional fusion partner & Reference \\
\hline Sleeping sickness & Trypanosomes & VSG oligomannose & Monovalent & Apolipoprotein L-I & Baral et al. 2006 \\
\hline Infant diarrhea & Rotavirus & Unknown & Monovalent & None & $\begin{array}{l}\text { Van der Vaart et al. } \\
2006\end{array}$ \\
\hline Infant diarrhea & Rotavirus & Unknown & Monovalent & $\begin{array}{l}\text { Lactobacillus cell-surface } \\
\text { anchor }\end{array}$ & Pant et al. 2006 \\
\hline Piglet diarrhea & E. coli & F4 fimbriae & Monovalent & None & Harmsen et al. 2006 \\
\hline Caries & S. mutans & I/II adhesion & Monovalent & None & Kruger et al. 2006 \\
\hline FMD & FMD virus & VP1 & Monovalent & PEG & Harmsen et al. 2007 \\
\hline Sepsis & $\begin{array}{l}N . \\
\quad \text { meningitidis }\end{array}$ & LPS & Monovalent & None & $\begin{array}{l}\text { El Khattabi et al. } \\
2006\end{array}$ \\
\hline Cancer & - & CEA & Monovalent & $\beta$-Lactamase & $\begin{array}{l}\text { Cortez-Retamozo et } \\
\text { al. } 2004\end{array}$ \\
\hline Cancer & - & EGF receptor & Bivalent & Anti-albumin VHH & Roovers et al. 2007 \\
\hline Rheumatoid arthritis & - & $\mathrm{TNF} \alpha$ & Bivalent & Anti-albumin VHH & Coppieters et al. 2006 \\
\hline Brain disorders & - & $\begin{array}{l}\alpha(2,3)- \\
\text { Sialoglycoprotein }\end{array}$ & Monovalent & None & $\begin{array}{l}\text { Muruganandam et al. } \\
2002\end{array}$ \\
\hline $\begin{array}{l}\text { Neurodegenerative } \\
\text { diseases }\end{array}$ & - & $\mathrm{Bax}$ & Monovalent & None & $\begin{array}{l}\text { Gueorguieva et al. } \\
2006\end{array}$ \\
\hline
\end{tabular}

protection (Kruger et al. 2006). Because these VHHs should function in the oral cavity, the low level of protection cannot be due to proteolytic VHH degradation within the gastrointestinal tract.

The short serum half-life because of a rapid renal clearance limits the efficacy of VHHs in many parenteral applications. Therefore, VHHs have been targeted to normally long-lived serum proteins such as albumin (Coppieters et al. 2006; Roovers et al. 2007) or immunoglobulin (Harmsen et al. 2005a) using bispecific VHHs recognizing these serum proteins in addition to the therapeutic target, resulting in half-lives that equal the half-life of albumin ( 2 days in mice) and immunoglobulin (9 days). An alternative well-known approach to increase serum half-life of proteins is the chemical addition of polyethylene glycol (PEG). Such PEGylation of foot-andmouth disease (FMD) virus-neutralizing VHHs not only increased serum half-life but also increased in vitro neutralizing potency to levels above that of the hyperimmune serum (Harmsen et al. 2007). However, in contrast to the full protection afforded by the hyperimmune serum, these VHHs poorly protected guinea pigs from FMD viral challenge infection, suggesting that Fc-mediated effector functions are required for efficient in vivo protection (Harmsen et al. 2007).

Nevertheless, many diseases were successfully treated with VHHs in the absence of Fc-mediated effector functions. These VHHs either are used as targeting devices for toxic enzymes or block a specific molecular interaction. For example, sleeping sickness was successfully treated with VHHs that bind to a trypanosome coat protein and were fused to the apolipoprotein L-1 enzyme, resulting in trypanosome lysis (Baral et al. 2006). In oncology, a VHH directed against carcinoembryonic antigen was used for targeting the genetically fused $\beta$ lactamase to tumor cells. This enzyme then converts an injected nontoxic prodrug into a toxic drug in the vicinity of the targeted tumor cells, leading to their killing (CortezRetamozo et al. 2004). Several VHH therapies are also being developed for treatment of oncology or inflammatory diseases based on blocking molecular interactions. VHHs binding to epidermal growth factor receptor (EGFR) can block epidermal growth factor (EGF) binding to its receptor, which can be used to treat solid tumors (Roovers et al. 2007). Tenfold more potent EGFR-binding VHHs could be obtained by construction of bivalent formats. It is interesting to note that the recently approved conventional antibody Panitumumab directed against EGFR also blocks EGF binding and is expected to give poor ADCC and CDC (Reichert and Valge-Archer 2007). Furthermore, by blocking receptor interaction, VHHs binding to tumor necrosis factor- $\alpha$ can be used for treatment of rheumatoid arthritis (Coppieters et al. 2006). The potency of bivalent formats was 500-fold increased as compared to monovalent VHHs and even exceeded the potency of clinically used conventional antibodies both in vitro and in a murine arthritis model. Similarly, lipopolysaccharide (LPS)-binding VHHs were isolated that block LPS binding and signaling to host cells for treatment of sepsis (El Khattabi et al. 2006).

The potential immunogenicity of VHHs could compromise their parenteral therapeutic use, especially in treat- 
ments that require repeated injections. Until now, multiple injections of VHHs have not shown any immunogenicity in mice, as assessed by the presence of specific antibodies, $\mathrm{T}$ cell proliferation, or cytokine levels (Cortez-Retamozo et al. 2002; Coppieters et al. 2006). This could rely on their high sequence homology to conventional $\mathrm{VH}$ domains and on their high stability because aggregation of proteins is known to increase immunogenicity (Hermeling et al. 2004). If necessary, technologies developed to decrease immunogenicity of mouse monoclonal antibodies (Presta 2006) could also be applied to VHHs. Alternatively, immunogenicity could be reduced by the use of conventional-like VHHs, which have an even higher structural homology to conventional VH domains.

For their use in targeting drugs across the blood-brain barrier (BBB) into the brain, VHHs were selected that transmigrate the human $\mathrm{BBB}$ in an in vitro model and accumulate in the brain after intravenous injection into mice (Muruganandam et al. 2002). These could be used for treatment of neurological disorders. Finally, Bax-specific VHHs have been expressed in the cytoplasm, resulting in so-called intrabodies, to prevent oxidative-stress-induced apoptosis that is implicated in several neurodegenerative diseases (Gueorguieva et al. 2006). Because of their stability, VHHs are especially suited for intrabody production because this requires expression in the reducing environment of the cytoplasm (Gueorguieva et al. 2006; Rothbauer et al. 2006).

\section{Conclusions}

Since the discovery of heavy-chain antibodies in 1993, the field of single-domain antibody fragments has been rapidly growing. VHHs have many advantages for biotechnological applications. They can be economically produced in microorganisms and have a high stability. Furthermore, they are highly suited for expression as multivalent, including bispecific, formats or as enzyme fusions. This permits a plug-and-play approach, where, depending on the target, biology potency can be increased by multivalent constructs or bispecific VHH recognizing two different targets can be made. This also enables the tailor-made design of serum half-life using site-directed PEGylation or by targeting to long-lived serum proteins using bispecific VHHs. Although fusions of targeting VHHs to Ig-binding VHHs or Fc can be used to recruit effector functions most current research on VHHs focuses on therapeutic applications where such effector functions are not required. Finally, conventional whole antibodies occasionally give side effects because of their bivalent nature, which can result in target crosslinking, or the presence of the Fc region. Evidently, such side effects are not expected to occur using monovalent
VHHs. This, however, is yet to be confirmed as the first VHH has entered phase I clinical trials in 2007 (http:// www.ablynx.com).

\section{References}

Alvarez-Rueda N, Behar G, Ferre V, Pugniere M, Roquet F, Gastinel L, Jacquot C, Aubry J, Baty D, Barbet J, Birkle S (2007) Generation of llama single-domain antibodies against methotrexate, a prototypical hapten. Mol Immunol 44:1680-1690

Arbabi-Ghahroudi M, Desmyter A, Wyns L, Hamers R, Muyldermans S (1997) Selection and identification of single domain antibody fragments from camel heavy-chain antibodies. FEBS Lett 414:521-526

Arbabi-Ghahroudi M, Tanha J, MacKenzie R (2005) Prokaryotic expression of antibodies. Cancer Metastasis Rev 24:501-519

Baral TN, Magez S, Stijlemans B, Conrath K, Vanhollebeke B, Pays E, Muyldermans S, De Baetselier P (2006) Experimental therapy of African trypanosomiasis with a nanobody-conjugated human trypanolytic factor. Nat Med 12:580-584

Bond CJ, Marsters JC, Sidhu SS (2003) Contributions of CDR3 to VHH domain stability and the design of monobody scaffolds for naive antibody libraries. J Mol Biol 332:643-655

Conrath KE, Lauwereys M, Galleni M, Matagne A, Frere JM, Kinne J, Wyns L, Muyldermans S (2001a) Beta-lactamase inhibitors derived from single-domain antibody fragments elicited in the camelidae. Antimicrob Agents Chemother 45:2807-2812

Conrath KE, Lauwereys M, Wyns L, Muyldermans S (2001b) Camel single-domain antibodies as modular building units in bispecific and bivalent antibody constructs. J Biol Chem 276:7346-7350

Conrath KE, Vincke C, Stijlemans B, Schymkowitz J, Decanniere K, Wyns L, Muyldermans S, Loris R (2005) Antigen binding and solubility effects upon the veneering of a camel VHH in framework-2 to mimic a VH. J Mol Biol 350:112-125

Coppieters K, Dreier T, Silence K, de Haard H, Lauwereys M, Casteels P, Beirnaert E, Jonckheere H, Van de Wiele C, Staelens L, Hostens J, Revets H, Remaut E, Elewaut D, Rottiers P (2006) Formatted anti-tumor necrosis factor alpha VHH proteins derived from camelids show superior potency and targeting to inflamed joints in a murine model of collagen-induced arthritis. Arthritis Rheum 54:1856-1866

Cortez-Retamozo V, Lauwereys M, Hassanzadeh Gh G, Gobert M, Conrath K, Muyldermans S, De Baetselier P, Revets H (2002) Efficient tumor targeting by single-domain antibody fragments of camels. Int J Cancer 98:456-462

Cortez-Retamozo V, Backmann N, Senter PD, Wernery U, De Baetselier P, Muyldermans S, Revets H (2004) Efficient cancer therapy with a nanobody-based conjugate. Cancer Res 64:2853-2857

Davies J, Riechmann L (1995) Antibody VH domains as small recognition units. Biotechnology (NY) 13:475-479

Davies J, Riechmann L (1996) Single antibody domains as small recognition units: design and in vitro antigen selection of camelized, human VH domains with improved protein stability. Protein Eng 9:531-537

De Genst E, Silence K, Decanniere K, Conrath K, Loris R, Kinne J, Muyldermans S, Wyns L (2006) Molecular basis for the preferential cleft recognition by dromedary heavy-chain antibodies. Proc Natl Acad Sci USA 103:4586-4591

Desmyter A, Transue TR, Ghahroudi MA, Thi MH, Poortmans F, Hamers R, Muyldermans S, Wyns L (1996) Crystal structure of a camel single-domain $\mathrm{VH}$ antibody fragment in complex with lysozyme. Nat Struct Biol 3:803-811 
Desmyter A, Decanniere K, Muyldermans S, Wyns L (2001) Antigen specificity and high affinity binding provided by one single loop of a camel single-domain antibody. J Biol Chem 276:2628526290

Dolk E, van der Vaart M, Lutje Hulsik D, Vriend G, de Haard H, Spinelli S, Cambillau C, Frenken L, Verrips T (2005) Isolation of llama antibody fragments for prevention of dandruff by phage display in shampoo. Appl Environ Microbiol 71:442-450

Dufner P, Jermutus L, Minter RR (2006) Harnessing phage and ribosome display for antibody optimisation. Trends Biotechnol 24:523-529

Dumoulin M, Conrath K, Van Meirhaeghe A, Meersman F, Heremans K, Frenken LG, Muyldermans S, Wyns L, Matagne A (2002) Single-domain antibody fragments with high conformational stability. Protein Sci 11:500-515

Dumoulin M, Last AM, Desmyter A, Decanniere K, Canet D, Larsson G, Spencer A, Archer DB, Sasse J, Muyldermans S, Wyns L, Redfield C, Matagne A, Robinson CV, Dobson CM (2003) A camelid antibody fragment inhibits the formation of amyloid fibrils by human lysozyme. Nature 424:783-788

El Khattabi M, Adams H, Heezius E, Hermans P, Detmers F, Maassen B, van der Ley P, Tommassen J, Verrips T, Stam J (2006) Llama single-chain antibody that blocks lipopolysaccharide binding and signaling: prospects for therapeutic applications. Clin Vaccine Immunol 13:1079-1086

Estell D (2006) Adapting industry practices for the rapid, large-scale manufacture of pharmaceutical proteins. Bridge 36:39-44

Ewert S, Cambillau C, Conrath K, Pluckthun A (2002) Biophysical properties of camelid $\mathrm{V}(\mathrm{HH})$ domains compared to those of human $\mathrm{V}(\mathrm{H}) 3$ domains. Biochemistry 41:3628-3636

Frenken LGJ, van der Linden RH, Hermans PW, Bos JW, Ruuls RC, de Geus B, Verrips CT (2000) Isolation of antigen specific llama VHH antibody fragments and their high level secretion by Saccharomyces cerevisiae. J Biotechnol 78:11-21

Gerngross TU (2004) Advances in the production of human therapeutic proteins in yeasts and filamentous fungi. Nat Biotechnol 22:1409-1414

Glockshuber R, Malia M, Pfitzinger I, Pluckthun A (1990) A comparison of strategies to stabilize immunoglobulin Fv-fragments. Biochemistry 29:1362-1367

Goldman ER, Anderson GP, Liu JL, Delehanty JB, Sherwood LJ, Osborn LE, Cummins LB, Hayhurst A (2006) Facile generation of heat-stable antiviral and antitoxin single domain antibodies from a semisynthetic llama library. Anal Chem 78: 8245-8255

Greenberg AS, Avila D, Hughes M, Hughes A, McKinney EC, Flajnik MF (1995) A new antigen receptor gene family that undergoes rearrangement and extensive somatic diversification in sharks. Nature 374:168-173

Gueorguieva D, Li S, Walsh N, Mukerji A, Tanha J, Pandey S (2006) Identification of single-domain, Bax-specific intrabodies that confer resistance to mammalian cells against oxidative-stressinduced apoptosis. FASEB J 20:2636-2638

Hamers-Casterman C, Atarhouch T, Muyldermans S, Robinson G, Hamers C, Songa EB, Bendahman N, Hamers R (1993) Naturally occurring antibodies devoid of light chains. Nature 363:446-448

Hamilton SR, Davidson RC, Sethuraman N, Nett JH, Jiang Y, Rios S, Bobrowicz P, Stadheim TA, Li H, Choi BK, Hopkins D, Wischnewski H, Roser J, Mitchell T, Strawbridge RR, Hoopes J, Wildt S, Gerngross TU (2006) Humanization of yeast to produce complex terminally sialylated glycoproteins. Science 313:1441-1443

Harmsen MM, Ruuls RC, Nijman IJ, Niewold TA, Frenken LGJ, de Geus B (2000) Llama heavy-chain V regions consist of at least four distinct subfamilies revealing novel sequence features. Mol Immunol 37:579-590
Harmsen MM, Van Solt CB, Fijten HPD, Van Setten MC (2005a) Prolonged in vivo residence times of llama single-domain antibody fragments in pigs by binding to porcine immunoglobulins. Vaccine 23:4926-4934

Harmsen MM, van Solt CB, Hoogendoorn A, van Zijderveld FG, Niewold TA, van der Meulen J (2005b) Escherichia coli F4 fimbriae specific llama single-domain antibody fragments effectively inhibit bacterial adhesion in vitro but poorly protect against diarrhoea. Vet Microbiol 111:89-98

Harmsen MM, van Solt CB, van Zijderveld-van Bemmel AM, Niewold TA, van Zijderveld FG (2006) Selection and optimization of proteolytically stable llama single-domain antibody fragments for oral immunotherapy. Appl Microbiol Biotechnol 72:544-551

Harmsen MM, Van Solt CB, Fijten HPD, Van Keulen L, Rosalia RA, Weerdmeester K, Cornelissen AHM, De Bruin MGM, Eblé PL, Dekker A (2007) Passive immunization of guinea-pigs with llama single-domain antibody fragments against foot-and-mouth disease. Vet Microbiol 120:193-206

Harrison RA, Hasson SS, Harmsen M, Laing GD, Conrath K, Theakston RD (2006) Neutralisation of venom-induced haemorrhage by $\operatorname{IgG}$ from camels and llamas immunised with viper venom and also by endogenous, non-IgG components in camelid sera. Toxicon 47:364-368

Hermeling S, Crommelin DJ, Schellekens H, Jiskoot W (2004) Structure-immunogenicity relationships of therapeutic proteins. Pharm Res 21:897-903

Holliger P, Hudson PJ (2005) Engineered antibody fragments and the rise of single domains. Nat Biotechnol 23:1126-1136

Holliger P, Wing M, Pound JD, Bohlen H, Winter G (1997) Retargeting serum immunoglobulin with bispecific diabodies. Nat Biotechnol 15:632-636

Janssens R, Dekker S, Hendriks RW, Panayotou G, van Remoortere A, San JK, Grosveld F, Drabek D (2006) Generation of heavychain-only antibodies in mice. Proc Natl Acad Sci USA 103:15130-15135

Jespers L, Schon O, Famm K, Winter G (2004) Aggregation-resistant domain antibodies selected on phage by heat denaturation. Nat Biotechnol 22:1161-1165

Joosten V, Roelofs MS, van den Dries N, Goosen T, Verrips CT, van den Hondel CA, Lokman BC (2005) Production of bifunctional proteins by Aspergillus awamori: llama variable heavy chain antibody fragment ( $\mathrm{V}(\mathrm{HH}))$ R9 coupled to Arthromyces ramosus peroxidase (ARP). J Biotechnol 120:347-359

Kruger C, Hultberg A, Marcotte H, Hermans P, Bezemer S, Frenken LG, Hammarstrom L (2006) Therapeutic effect of llama derived VHH fragments against Streptococcus mutans on the development of dental caries. Appl Microbiol Biotechnol 72:732-737

Lange IG, Daxenberger A, Meyer HH (2001) Studies on the antibody response of Lama glama - evaluation of the binding capacity of different IgG subtypes in ELISAs for clenbuterol and BSA. Vet Immunol Immunopathol 83:1-9

Lauwereys M, Arbabi Ghahroudi M, Desmyter A, Kinne J, Holzer W, De Genst E, Wyns L, Muyldermans S (1998) Potent enzyme inhibitors derived from dromedary heavy-chain antibodies. Embo J 17:3512-3520

Lesk AM, Chothia C (1988) Elbow motion in the immunoglobulins involves a molecular ball-and-socket joint. Nature 335:188-190

Muruganandam A, Tanha J, Narang S, Stanimirovic D (2002) Selection of phage-displayed llama single-domain antibodies that transmigrate across human blood-brain barrier endothelium. Faseb J 16:240-242

Muyldermans S (2001) Single domain camel antibodies: current status. J Biotechnol 74:277-302

Muyldermans S, Atarhouch T, Saldanha J, Barbosa JA, Hamers R (1994) Sequence and structure of VH domain from naturally 
occurring camel heavy chain immunoglobulins lacking light chains. Protein Eng 7:1129-35

Muyldermans S, Cambillau C, Wyns L (2001) Recognition of antigens by single-domain antibody fragments: the superfluous luxury of paired domains. Trends Biochem Sci 26:230-235

Nguyen VK, Hamers R, Wyns L, Muyldermans S (2000) Camel heavy-chain antibodies: diverse germline $\mathrm{V}(\mathrm{H}) \mathrm{H}$ and specific mechanisms enlarge the antigen-binding repertoire. Embo $\mathrm{J}$ 19:921-930

Nguyen VK, Zou X, Lauwereys M, Brys L, Bruggemann M, Muyldermans S (2003) Heavy-chain only antibodies derived from dromedary are secreted and displayed by mouse B cells. Immunology 109:93-101

Nieba L, Honegger A, Krebber C, Pluckthun A (1997) Disrupting the hydrophobic patches at the antibody variable/constant domain interface: improved in vivo folding and physical characterization of an engineered scFv fragment. Protein Eng 10:435-444

Nowakowski A, Wang C, Powers DB, Amersdorfer P, Smith TJ, Montgomery VA, Sheridan R, Blake R, Smith LA, Marks JD (2002) Potent neutralization of botulinum neurotoxin by recombinant oligoclonal antibody. Proc Natl Acad Sci USA 99:1134611350

Olichon A, Schweizer D, Muyldermans S, de Marco A (2007) Heating as a rapid purification method for recovering correctly-folded thermotolerant $\mathrm{VH}$ and $\mathrm{VHH}$ domains. BMC Biotechnol 7:7

Pant N, Hultberg A, Zhao Y, Svensson L, Pan-Hammarstrom Q, Johansen K, Pouwels PH, Ruggeri FM, Hermans P, Frenken L, Boren T, Marcotte H, Hammarstrom L (2006) Lactobacilli expressing variable domain of llama heavy-chain antibody fragments (lactobodies) confer protection against rotavirusinduced diarrhea. J Infect Dis 194:1580-1588

Perez JM, Renisio JG, Prompers JJ, van Platerink CJ, Cambillau C, Darbon H, Frenken LG (2001) Thermal unfolding of a llama antibody fragment: a two-state reversible process. Biochemistry 40:74-83

Pleschberger M, Saerens D, Weigert S, Sleytr UB, Muyldermans S, Sara M, Egelseer EM (2004) An S-layer heavy chain camel antibody fusion protein for generation of a nanopatterned sensing layer to detect the prostate-specific antigen by surface plasmon resonance technology. Bioconjug Chem 15:664-671

Presta LG (2006) Engineering of therapeutic antibodies to minimize immunogenicity and optimize function. Adv Drug Deliv Rev 58:640-656

Rahbarizadeh F, Rasaee MJ, Forouzandeh-Moghadam M, Allameh AA (2005) High expression and purification of the recombinant camelid anti-MUC1 single domain antibodies in Escherichia coli. Protein Expr Purif 44:32-38

Rahbarizadeh F, Rasaee MJ, Forouzandeh M, Allameh AA (2006) Over expression of anti-MUC1 single-domain antibody fragments in the yeast Pichia pastoris. Mol Immunol 43:426-435

Reichert JM, Valge-Archer VE (2007) Development trends for monoclonal antibody cancer therapeutics. Nat Rev Drug Discov 6:349-356

Revets H, De Baetselier P, Muyldermans S (2005) Nanobodies as novel agents for cancer therapy. Expert Opin Biol Ther 5:111-124

Roovers RC, Laeremans T, Huang L, De Taeye S, Verkleij AJ, Revets H, De Haard HJ, Van Bergen en Henegouwen PM (2007) Efficient inhibition of EGFR signaling and of tumour growth by antagonistic anti-EFGR Nanobodies. Cancer Immunol Immunother 56:303-317

Rothbauer U, Zolghadr K, Tillib S, Nowak D, Schermelleh L, Gahl A, Backmann N, Conrath K, Muyldermans S, Cardoso MC, Leonhardt H (2006) Targeting and tracing antigens in live cells with fluorescent nanobodies. Nat Methods 3:887-889

Saerens D, Kinne J, Bosmans E, Wernery U, Muyldermans S, Conrath K (2004) Single domain antibodies derived from dromedary lymph node and peripheral blood lymphocytes sensing conformational variants of prostate-specific antigen. J Biol Chem 279:51965-51972

Sagt CM, Kleizen B, Verwaal R, de Jong MD, Muller WH, Smits A, Visser C, Boonstra J, Verkleij AJ, Verrips CT (2000) Introduction of an N-glycosylation site increases secretion of heterologous proteins in yeasts. Appl Environ Microbiol 66:4940-4944

Sethuraman N, Stadheim TA (2006) Challenges in therapeutic glycoprotein production. Curr Opin Biotechnol 17:341-346

Simmons DP, Abregu FA, Krishnan UV, Proll DF, Streltsov VA, Doughty L, Hattarki MK, Nuttall SD (2006) Dimerisation strategies for shark IgNAR single domain antibody fragments. J Immunol Methods 315:171-184

Spinelli S, Frenken L, Bourgeois D, de Ron L, Bos W, Verrips T, Anguille C, Cambillau C, Tegoni M (1996) The crystal structure of a llama heavy chain variable domain. Nat Struct Biol 3:752757

Spinelli S, Frenken LG, Hermans P, Verrips T, Brown K, Tegoni M, Cambillau C (2000) Camelid heavy-chain variable domains provide efficient combining sites to haptens. Biochemistry 39:1217-1222

Stijlemans B, Conrath K, Cortez-Retamozo V, Van Xong H, Wyns L, Senter P, Revets H, De Baetselier P, Muyldermans S, Magez S (2004) Efficient targeting of conserved cryptic epitopes of infectious agents by single domain antibodies. African trypanosomes as paradigm. J Biol Chem 279:1256-1261

Streltsov VA, Varghese JN, Carmichael JA, Irving RA, Hudson PJ, Nuttall SD (2004) Structural evidence for evolution of shark Ig new antigen receptor variable domain antibodies from a cellsurface receptor. Proc Natl Acad Sci USA 101:12444-12449

Sundberg EJ, Mariuzza RA (2002) Molecular recognition in antibodyantigen complexes. Adv Protein Chem 61:119-160

Tanha J, Dubuc G, Hirama T, Narang SA, MacKenzie CR (2002) Selection by phage display of llama conventional $\mathrm{V}(\mathrm{H})$ fragments with heavy chain antibody $\mathrm{V}(\mathrm{H}) \mathrm{H}$ properties. J Immunol Methods 263:97-109

Thomassen YE, Meijer W, Sierkstra L, Verrips CT (2002) Large-scale production of VHH antibody fragments by Saccharomyces cerevisiae. Enzyme Microb Technol 30:273-278

Thomassen YE, Verkleij AJ, Boonstra J, Verrips CT (2005) Specific production rate of VHH antibody fragments by Saccharomyces cerevisiae is correlated with growth rate, independent of nutrient limitation. J Biotechnol 118:270-277

Utsumi S, Karush F (1964) The subunits of purified rabbit antibody. Biochemistry 3:1329-1338

Van de Laar T, Visser C, Holster M, Lopez CG, Kreuning D, Sierkstra L, Lindner N, Verrips T (2007) Increased heterologous protein production by Saccharomyces cerevisiae growing on ethanol as sole carbon source. Biotechnol Bioeng 96:483-494

Van der Linden RH, Frenken LG, De Geus B, Harmsen MM, Ruuls RC, Stok W, de Ron L, Wilson S, Davis P, Verrips CT (1999) Comparison of physical chemical properties of llama $\mathrm{VHH}$ antibody fragments and mouse monoclonal antibodies. Biochim Biophys Acta 1431:37-46

Van der Linden R, De Geus B, Stok W, Bos W, Van Wassenaar D, Verrips T, Frenken L (2000a) Induction of immune responses and molecular cloning of the heavy chain antibody repertoire of Lama glama. J Immunol Methods 240:185-195

Van der Linden RH, De Geus B, Frenken GJ, Peters H, Verrips CT (2000b) Improved production and function of llama heavy chain antibody fragments by molecular evolution. J Biotechnol $80: 261-270$

Van der Vaart JM (2002) Expression of VHH antibody fragments in Saccharomyces cerevisiae. In: O'Brien PM, Aitken R (eds) Methods in molecular biology, vol 178. Antibody phage display: methods and protocols. Humana, Totowa, NJ, pp 359-366 
Van der Vaart JM, Pant N, Wolvers D, Bezemer S, Hermans PW, Bellamy $\mathrm{K}$, Sarker SA, van der Logt CP, Svensson L, Verrips CT, Hammarstrom L, van Klinken BJ (2006) Reduction in morbidity of rotavirus induced diarrhoea in mice by yeast produced monovalent llama-derived antibody fragments. Vaccine 24:4130-4137

Verheesen P, ten Haaft MR, Lindner N, Verrips CT, de Haard JJ (2003) Beneficial properties of single-domain antibody fragments for application in immunoaffinity purification and immunoperfusion chromatography. Biochim Biophys Acta 1624:21-28

Verheesen P, Roussis A, de Haard HJ, Groot AJ, Stam JC, den Dunnen JT, Frants RR, Verkleij AJ, Verrips CT, van der Maarel SM (2006) Reliable and controllable antibody fragment selections from camelid non-immune libraries for target validation. Biochim Biophys Acta 1764:1307-1319

Vu KB, Ghahroudi MA, Wyns L, Muyldermans S (1997) Comparison of llama VH sequences from conventional and heavy chain antibodies. Mol Immunol 34:1121-1131

Ward ES, Gussow D, Griffiths AD, Jones PT, Winter G (1989) Binding activities of a repertoire of single immunoglobulin variable domains secreted from Escherichia coli. Nature 341:544-546
Whitlow M, Bell BA, Feng SL, Filpula D, Hardman KD, Hubert SL, Rollence ML, Wood JF, Schott ME, Milenic DE et al (1993) An improved linker for single-chain Fv with reduced aggregation and enhanced proteolytic stability. Protein Eng 6:989995

Yau KY, Groves MA, Li S, Sheedy C, Lee H, Tanha J, MacKenzie CR, Jermutus L, Hall JC (2003) Selection of hapten-specific single-domain antibodies from a non-immunized llama ribosome display library. J Immunol Methods 281:161-175

Yoo TJ, Roholt OA, Pressman D (1967) Specific binding activity of isolated light chains of antibodies. Science 157:707-709

Zhang J, Tanha J, Hirama T, Khieu NH, To R, Tong-Sevinc H, Stone E, Brisson JR, MacKenzie CR (2004) Pentamerization of singledomain antibodies from phage libraries: a novel strategy for the rapid generation of high-avidity antibody reagents. J Mol Biol 335:49-56

Zwick MB, Parren PW, Saphire EO, Church S, Wang M, Scott JK, Dawson PE, Wilson IA, Burton DR (2003) Molecular features of the broadly neutralizing immunoglobulin G1 b12 required for recognition of human immunodeficiency virus type $1 \mathrm{gp} 120$. J Virol 77:5863-5876 